\title{
Jäähdytyksellä suljettuun kasvihuoneeseen
}

\author{
Risto Tahvonen \\ MTT Puutarhatuotanto, Toivonlinnantie 518,21500 Piikkiö, etunimi.sukunimi@mtt.fi
}

\section{Tiivistelmä}

Nykyaikaisessa ympärivuotisessa kasvihuonetuotannossa käytetään tekovaloja $150-250 \mathrm{~W} / \mathrm{m}^{2}$, jos auringon säteily on kasvun kannalta liian vähäistä. Tässä tuotantotavassa on alhaisin satotaso kesäaikana, koska kasvihuoneen lämpötila nousee liian korkeaksi ja kasvihuoneilman hiilidioksidipitoisuutta ei voida pitää optimina tuuletuksen takia. Päivittäinen tuuletusaika on huhtikuusta syyskuuhun yleensä yli 8 tuntia parhaimman valon aikaan, jolloin potentiaalinen hyvä sato jää saamatta. Avointa kasvihuonetta jäähdytetään sumuttamalla, tuulettamalla ja varjostamalla. Jäähdytystarve on hyvin suuri, sillä auringosta tulee säteilyä pahimmillaan $800-1000 \mathrm{~W} / \mathrm{m}^{2}$, josta suuri osa muuttuu latentiksi lämmöksi kasvien haihdutuksessa. Uusiksi jäähdytysratkaisuksi tähän on haettu järjestelmiä, joissa kasvihuoneilma ja ulkoilma eivät sekoitu toisiinsa. Kaikille näille järjestelmille on yhteistä, että kasvihuoneilmasta on poistettava sekä vesihöyryyn sitoutunut että lämpöiseen ilmaan sitoutunut energia. Tästä syystä perinteiset jäähdytyskoneratkaisut eivät tule kysymykseen, sillä niiden tehokerroin parhaimmillaankin on 6-7, jolloin jäḧhdytyksen kustannus olisi taloudellisesti kestämätön.

Kasvihuoneiden jäähdytykseen on kehitetty neljä erilaista periaatteellista menetelmää. Vanhin ja edelleen eteläisimmissä maissa käytetty jäähdytysmenetelmä on kosteaseinämenetelmä, jossa kasvihuoneeseen puhalletaan ulkoilmaa kostean huovan tai pisaraverhon lävitse. Tässä menetelmässä kasvihuoneilma uusiutuu jatkuvasti, jolloin kasvihuoneen ilman hiilidioksidipitoisuus voidaan pitää vain ulkoilman pitoisuuden tasolla. Espanjassa on tutkimuskäytössä jäähdytystornimenetelmä, jossa suljetun kasvihuoneen yhteydessä on korkea torni, jonne kuuma ja kostea ilma nousee jäähtymään ja luovuttamaan kosteuden. Tämä menetelmä soveltuu vain trooppisille kasveille, jotka menestyvät 30$40{ }^{\circ} \mathrm{C}: n$ lämpötiloissa.

Hollannissa on kaupallisessa kokeilussa kasvihuoneen jäähdytys kylmällä pohjavedellä. Kylmää pohjavettä pumpataan kasvihuoneessa oleviin lämmönvaihtimiin ja lämmennyt pohjavesi palautetaan takaisin maahan, mutta kauaksi ottopaikastaan. Järjestelmä on kallis ja teknisesti monimutkainen ja se soveltuu vain kylmille pohjavesialueille.

Suomessa on kehitetty jäähdytystekniikka, joka perustuu kasvihuoneen sisällä olevaan kapeaan pisaraverhoon, johon kasvihuoneilmassa oleva energia siirtyy. Kiertävä vesi jäähdytetään kasvihuoneen ulkopuolella olevassa jäähdytysaltaassa suihkuhaihduttimella. Järjestelmän tehokerroin on noin 50. Keväällä ja syksyllä, kun ulkoaltaan lämpötila on alhainen, tehokertoimeksi tulee jopa yli 100 . Pisaraverhojäähdytyksellä kasvihuoneen lämpötilan hallinta onnistuu myös kovimpina helleaikoina, mutta kosteuden poistamisessa on hetkellisiä ongelmia, kun jäähdytysaltaan ja ulkolämpötilan välinen ero ei ole tarpeeksi suuri.

Asiasanat: energia, hiilidioksidi, kasvihuoneilmasto, ilman kosteus, lämpötila, puolisuljettu kasvihuone 


\section{Johdanto}

Nykyaikaisessa ympärivuotisessa kasvihuonetuotannossa käytetään keinovaloja $150-250 \mathrm{~W} / \mathrm{m}^{2}$, jos auringon säteily on kasvun kannalta liian vähäistä. Tässä tuotantotavassa on alhaisin satotaso kesäaikana, koska kasvihuoneen lämpötila nousee liian korkeaksi ja kasvihuoneilman hiilidioksidipitoisuutta ei voida pitää optimina tuuletuksen takia. Päivittäinen tuuletusaika on huhtikuusta syyskuuhun yleensä yli 8 tuntia parhaimman valon aikaan, jolloin potentiaalinen hyvä sato jää toteutumatta (Hovi ym. 2004). Tästä syystä kasvihuoneolojen hallinnassa pyritään suljettuun kasvihuoneeseen, jota on tutkittu niin biologian kuin tekniikankin kannalta viime vuosien aikana erityisesti Espanjassa, Hollannissa ja Suomessa.

Tässä artikkelissa esitetty aineisto ja menetelmät perustuvat MTT puutarhatuotannossa tehtyihin lukuisiin kokeisiin ja on esitetty MTT puutarhatuotannon julkaisuissa Hovi ym.(2004), Särkkä (2004), Särkkä ym. (2006) ja Särkkä ym. (2008).

\section{Viljelyolot avoimessa kasvihuoneessa}

Kun kasvihuoneessa käytetään keinovaloja, kasvihuoneen tuuletustarve on samaa suuruusluokkaa kuin esimerkiksi Hollannissa. Kuvassa 1 on kuvattu kuinka kasvihuoneen molemmat tuuletusluukut ovat auki kesäkuun alusta elokuun loppuun yli 10 tuntia vuorokaudessa. Aktiivinen tuuletus vain toisella luukulla alkaa jo huhtikuun alusta ja loppuu lokakuun lopussa.

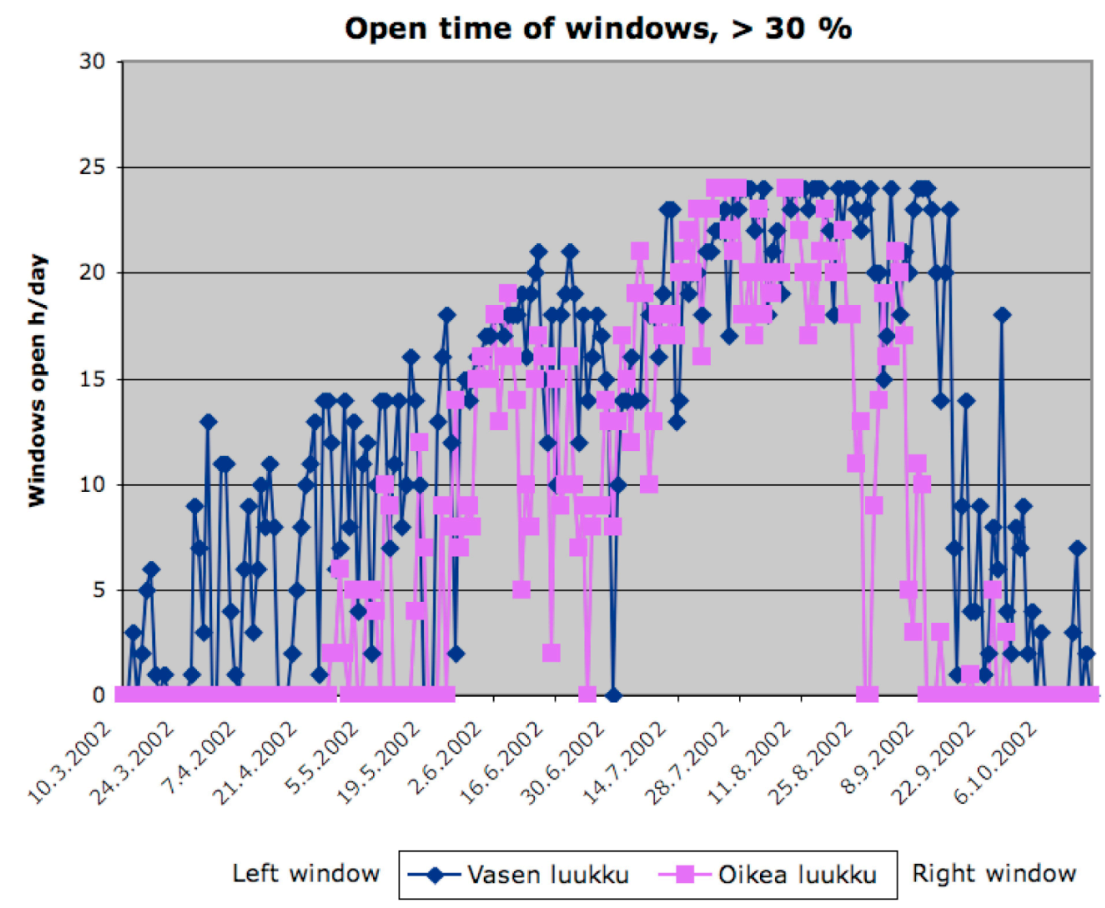

Kuva 1. Tuuletusluukkujen aukioloajat Piikkiössä olleessa kurkkukokeessa, kun kurkkukasvustoja valotetaan tekovalolla $20 \mathrm{~h} / \mathrm{d}$ aina, kun auringon säteilytaso $<\mathrm{n}$. $200 \mathrm{~W} / \mathrm{m}^{2}$. Luukkujen aukioloajaksi on laskettu tilanne, kun aukaisukulma on suurempi kuin $30 \%$ maksimista.

Kun tuuletusluukkujen aukaisukulma on yli $30 \%$ maksimista, kasvihuoneilmaan ei voida taloudellisesti lisätä hiilidioksidia. Tästä syystä loppukeväällä, kesällä ja alkusyksyllä kasvihuoneen hiilidioksidipitoisuudet ovat suurimman osan valoisasta ajasta ulkoilman hiilidioksidin tasolla. Tämä tilanne korostuu erityisesti ympärivuotisessa viljelyssä, josta kuvassa 2 on esitetty esimerkkinä keskimääräiset $\mathrm{CO}^{2}$-pitoisuudet eri vuorokauden aikoina viljelykuukausien keskiarvoina.

Perinteisesti tuulettamalla jäähdytetyssä kasvihuoneessa ympärivuotisessa viljelyssä, jossa käytetään tehokkaasti keinovaloa, viikoittaista sadon muodostusta kesällä kutsutaan MTT puutarhatuotannossa kasvun paradoksiksi, sillä runsasvaloisan kesäajan sato on merkittävästi pienempi kuin muina vuodenaikoina (kuva 3). Kesäaikainen heikko sato aiheutuu pääosin hiilidioksidin puutteesta ja kasvihuoneen liian korkeista lämpötiloista helleaikoina. 


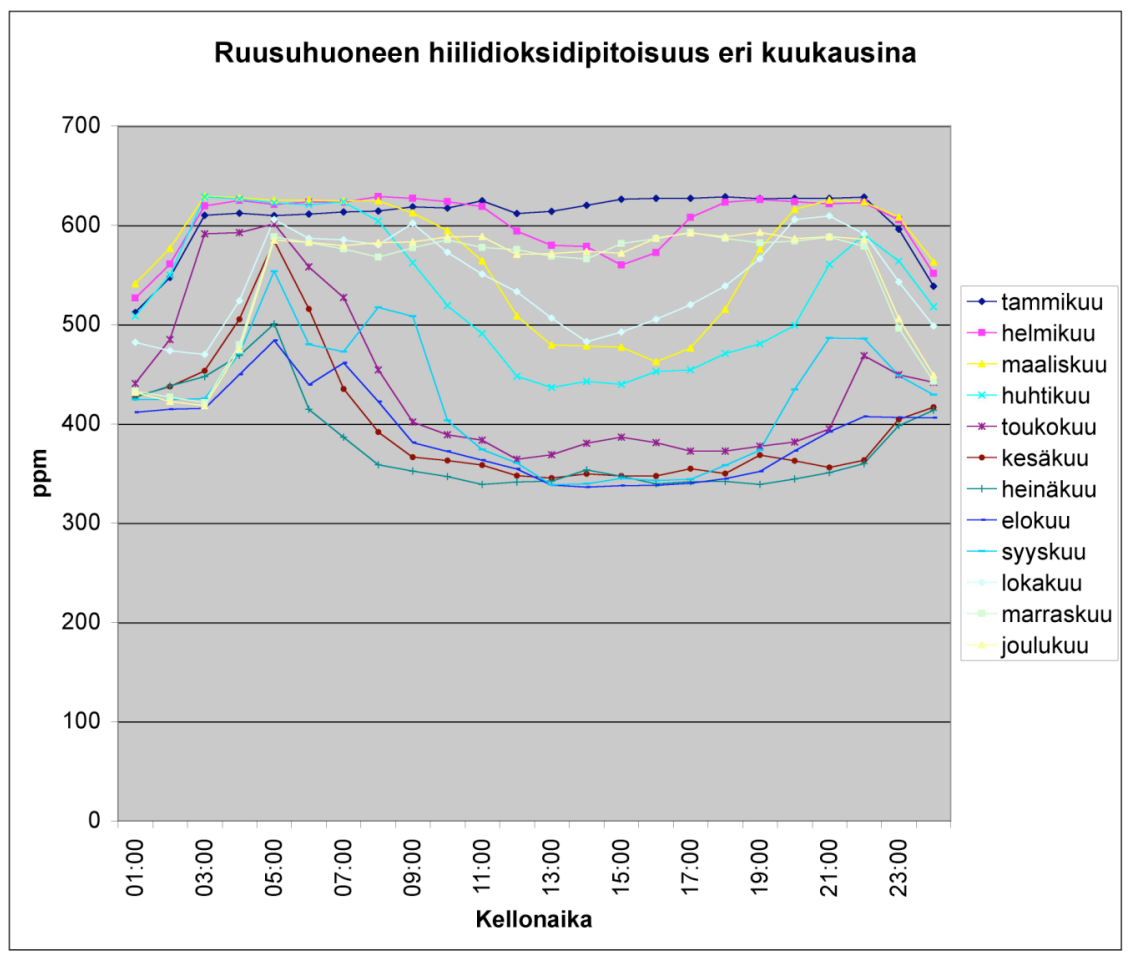

Kuva 2. Ruusuviljelyksen ilman kuukausittaiset hiilidioksidipitoisuudet luukkutuuletetussa kasvihuoneessa eri vuorokauden aikoina ympärivuotisessa viljelyssä, kun kasvien päivänpituus on $20 \mathrm{~h} / \mathrm{d}$. Kasveille annettu tekovaloa, kun auringon säteilyteho on ollut $<\mathrm{n} .200 \mathrm{~W} / \mathrm{m}^{2}$.

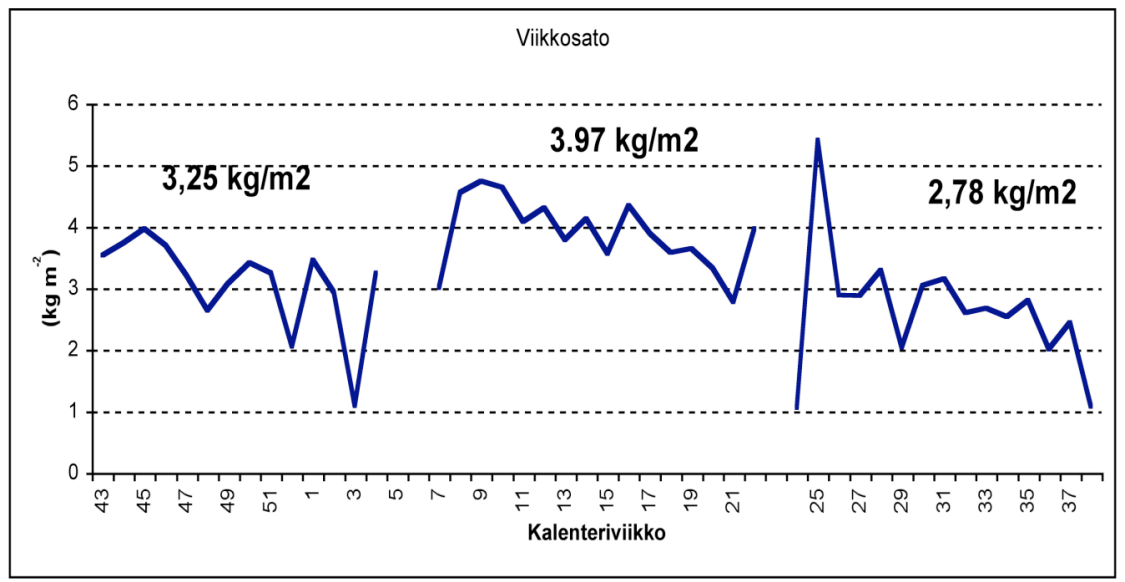

Kuva 3. Ympärivuotisesti viljellyn kasvihuonekurkun viikoittaiset sadot luukkutuuletetussa kasvihuoneessa kun kasvien päivänpituus on $20 \mathrm{~h} / \mathrm{d}$. Kasveille annettu tekovaloa, kun auringon säteilyteho on ollut $<\mathrm{n}$. $200 \mathrm{~W} / \mathrm{m}^{2}$.

Avointa kasvihuonetta jäähdytetään sumuttamalla, tuulettamalla ja varjostamalla. Jäähdytystarve on hyvin suuri, sillä auringosta tulee säteilyä enimmillään $800-1000 \mathrm{~W} / \mathrm{m}^{2}$, josta suuri osa muuttuu latentiksi lämmöksi kasvien haihdutuksessa. Kasvihuoneen ilman lämpötilan alentamiseksi tarvittava jäähdytystarve on olosuhteista riippuen $0-600 \mathrm{~W} / \mathrm{m}^{2}$. Uusiksi jäähdytysratkaisuksi tähän on haettu järjestelmiä, joissa kasvihuoneilma ja ulkoilma eivät sekoitu toisiinsa. Kaikille näille järjestelmille on yhteistä, että kasvihuoneilmasta on poistettava sekä vesihöyryyn sitoutunut että lämpöiseen ilmaan sitoutunut energia eli kasvihuoneesta on poistuttava aktiivisten ja passiivisten tekniikoiden avulla maksimissaan teholla $1000 \mathrm{~W} / \mathrm{m}^{2}$. Tästä syystä perinteiset jäähdytyskoneratkaisut eivät tule kysymykseen, sillä niiden tehokerroin parhaimmillaankin on 6-7, jolloin jäähdytyksen kustannus olisi taloudellisesti kestämätön. 
Koska perinteisillä tuuletustekniikoilla ei kyetä säätämään kasvihuoneoloja runsasvaloisana aikana kasvien tuotannon kannalta edullisiksi, on kasvihuonetekniikan kehityksessä viimeisten vuosien aikana keskitytty kehittämään puolisuljettua tai suljettua kasvihuonetta, joissa hiilidioksidin, ilman kosteuden ja lämpötilan hallinta on mahdollista toteuttaa kasvien kasvun kannalta mahdollisimman edullisesti. Suljetussa kasvihuoneessa saadaan hyvin merkittäviä sadonlisäyksiä kesäaikana (Särkkä ym. 2008).

\section{Kasvihuoneen energiavirrat}

Kasvihuoneeseen tulee energiaa auringon säteilystä, valotuksesta ja lämmityksestä. Ympärivuotisessa viljelyssä noin puolet energiasta tulee valaistuksesta ja loput auringon säteilystä ja lämmityksestä. Lämmityksen osuus on vain noin $10 \%$ kasvihuoneen vuosittaisesta, $2000 \mathrm{kWh} / \mathrm{m}^{2}$ kokonaisenergiavirrasta (kuva 4). Kaupallisessa kurkkukasvihuoneessa, jossa hiilidioksidin tuotannossa syntyvä energia otetaan talteen, seinillä on energiaverhot, lamppujen asennusteho on $250 \mathrm{~W} / \mathrm{m}^{2}$ ja kasveja valotetaan välivalotusmenetelmällä, perinteistä lämmitystä tarvitaan vain, jos ulkolämpötila on kylmempi kuin $-5--10{ }^{\circ} \mathrm{C}$ (Juntti 2009), jolloin nykyilmastossa lämmitystarve kaupallisessa kasvihuoneessa Etelä-Suomessa on pienempi kuin kuvassa 4 on esitetty.

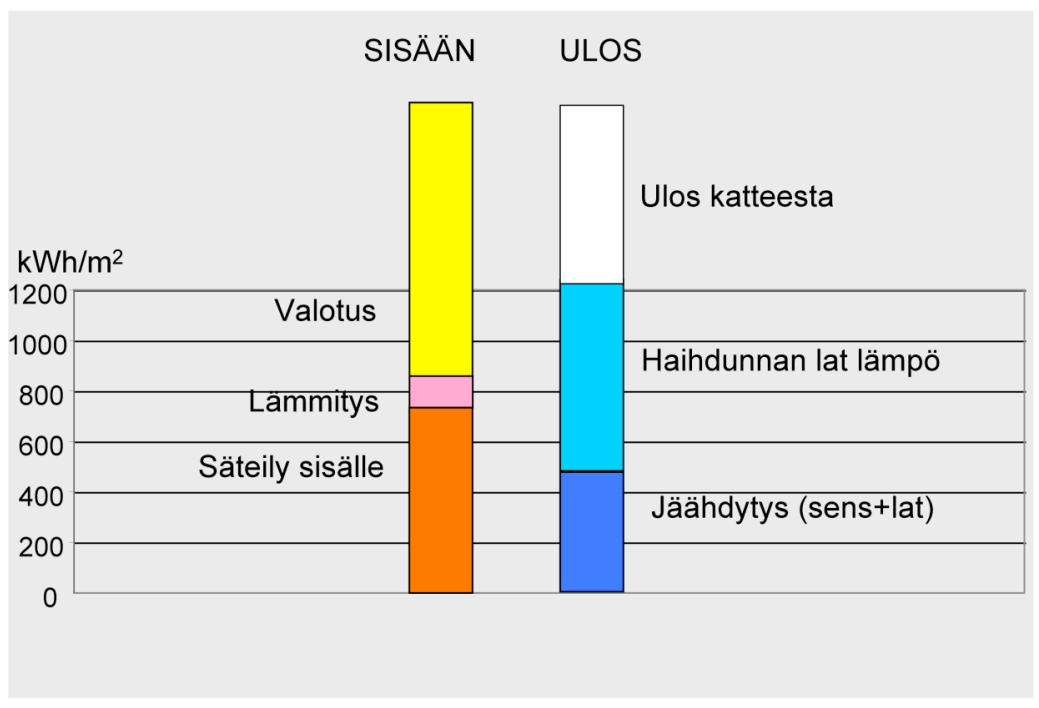

Kuva 4. Kasvihuoneen energiavirrat sisään ja ulos ympärivuotisessa kurkkuviljelyksessä MTT Piikkiön tutkimuskasvihuoneessa v. 2008-2009. Kasvihuone jäähdytetty pisaraverhomenetelmällä. Lamppujen asennusteho n. $200 \mathrm{~W} / \mathrm{m} 2$. Kasveille annettu tekovaloa, kun auringon säteilyteho on ollut < n. $200 \mathrm{~W} / \mathrm{m}^{2}$ (Kaukoranta 2009).

Kasvihuoneesta täytyy poistaa energiaa sama määrä kuin siihen tulee. Suurin osa kasvihuoneeseen tulevasta energiasta sitoutuu kasvutapahtumassa kasvien veden haihduntaan, mitä kautta energia poistuu kasvihuoneesta veden tiivistymisenä katteisiin ja jäähdytyksenä. Noin kolmannes kokonaisenergiasta poistuu kasvihuoneesta johtumalla katteen kautta. Merkittävä osuus energiasta on sitoutunut latentiksi lämmöksi vesihöyryyn ja hieman pienempi osa sensitiiviseksi lämmöksi ilmaan. Jäähdytyksen avulla kasvihuoneesta poistetaan sensitiivinen energia ja osa vesihöyryyn sitoutuneesta latentista energiasta (kuva 4) joko perinteisen luukkutuuletuksen tai jäähdytystekniikan avulla (Kaukoranta 2009).

\section{Kasvihuoneen jäähdytysmenetelmät}

Kosteaseinämenetelmä on vanhin ja eniten käytetty kasvihuoneilman jäähdytysmenetelmä. Tässä menetelmässä ulkoilma puhalletaan kasvihuoneeseen märän huopakerroksen tai pisaraverhon läpi, jolloin ulkoilma jäähtyy veden haihdutuksen ansiosta siirtyessään kasvihuoneeseen. Tämä menetelmä on paikoin käytössä mm. Arabimaissa ja USA:ssa. Tämä jäädytysmenetelmä toimii avoimena kasvihuoneena, sillä kasvihuoneen sisäilma ja ulkoilma sekoittuvat keskenään, jolloin hiilidioksidipitoisuus kasvihuoneessa on sama kuin ulkoilmassa. Kosteaseinäjäähdytyksestä on lukuisia eri sovelluksia (Montero 2006). 
Jäähdytystornimenetelmässä kasvihuoneen yhteydessä on korkea torni, jonne kasvihuoneen kuuma ja kostea ilma nousee. Ilman vesihöyry tiivistyy tornissa luovuttaen energiaa johtumalla ulkoilmaan. Tiivistynyt vesi on käytettävissä edelleen kasvien kasteluun. Tässä jäähdytysratkaisussa kasvihuoneen lämpötila pysyy Espanjan oloissa alle $36{ }^{\circ} \mathrm{C}$ :ssa. Menetelmä on toistaiseksi koeasteella ja on testattu vain eräillä trooppisilla kasveilla (Buchholz ym. 2006).

Baker ym. (2006) on kuvannut energiaa tuottavan kasvihuoneen, jossa kasvihuone jäähdytetään ja lämmitetään maahan varastoidulla energialla. Kasvihuoneeseen tuleva ja sieltä lähtevä energia sijoitetaan kahteen eri paikkaan, kylmään ja lämpöiseen alueeseen. Järjestelmässä tarvitaan tehokkaita lämmönvaihtimia, pumppuja ja lämpöpumppuja. "Yksinkertaistettu" sovellus tästä on maajäähdytystekniikkana kaupallisessa kokeilussa Hollannissa, missä maan sisässä olevaa kylmää pohjavettä käytetään kasvihuoneen jäähdytykseen. Lämminnyt pohjavesi palautetaan takaisin maaperään mutta kauaksi alkuperäisestä paikasta.

Suomessa on kehitetty pisaraverhojäähdytysmenetelmä (Huttunen 2009, www.novarbo.fi), jossa kasvihuoneessa on viileä pisaraverho jäähdyttämässä kasvihuonetta (kuva 5). Kasvihuoneilmassa oleva veso ja energia siirtyy tiivistymällä ja johtumalla laskeutuviin vesipisaroihin. Pisarat kerätään erikoisaltailla yhteen ja johdetaan putkia avulla ulkona olevaan altaaseen. Altaan vettä jäähdytetään suihkuhaihduttimilla, kun altaan lämpötila nousee yli halutun raja-arvon. Pisaraverho liikuttaa tehokkaasti kasvihuoneilmaa, jolloin erillisiä puhaltimia ei tarvita. Tässä menetelmässä tarvitaan vähän energiaa kuluttavia laitteita (veden kierrätyspumppu ja hiekkasuodatuksen pumppu), jolloin energiahyötysuhde on kaikkiin muihin menetelmiin verrattuna erittäin hyvä. Olosuhteista riippuen 1 kilowattitunnilla saadaan 50-100 kilowattitunnin jäähdytysenergia eli tehokerroin on 50-100. Kun pisaraverhon ja kasvihuoneilman lämpötilaero on riittävä, myös kasvihuoneen ilman liika kosteus voidaan poistaa tehokkaasti.

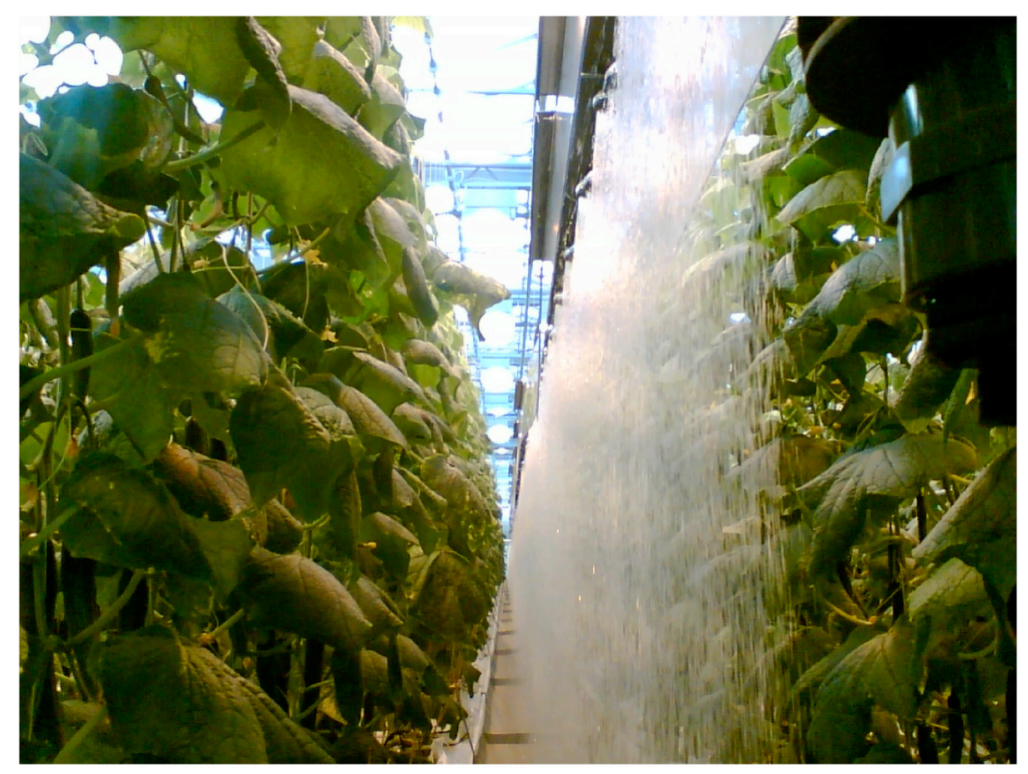

Kuva 5. Pisaraverhojäähdytyksessä kasvihuoneen latentti ja sensitiivinen lämpö siirtyvät putoaviin vesipisaroihin. Vesi jäähdytetään kasvihuoneen ulkopuolella olevassa suihkualtaassa.

\section{Johtopäätökset}

Tulevaisuuden kasvihuoneissa on käytössä energiatehokas jäähdytystekniikka, jolloin kasvihuone voidaan pitää suljettuna tai puolisuljettuna. Suljetussa kasvihuoneessa voidaan kasvihuoneen ilmasto säätää edulliseksi kasvien kasvulle, jolloin sadot nousevat merkitsevästi. Suljetusta kasvihuoneesta on myös merkittäviä etuja kasvinsuojelussa. 


\section{Kirjallisuus}

Bakker, J. C., de Zwart, H. F. \& Campen, J. B. 2006. Greenhouse Cooling and Heat Recovery using Fine Fire Heat Exchangers in a Closed Pot Plant Greenhouse: Design of an Energy Producing Greenhouse. Acta Horticulture 719: 263-270.

Biolan Oy. Finland. www.novarbo.fi.

Buchholz, M., Buchholz, R., Jochum, P., Zaragoza, G. \&Pérez-Parra, J. 2006. Temperature and humidity control in the watergy greenhouse. Acta Horticulturea 719: 401-407.

Hovi, T., Näkkilä, J., \& Tahvonen, R. 2004.Interlighting improves production of year-round cucumber. Scientia horticulturae 102, 3: 283-294.

Huttunen, J. 2009. Novarbo - closed greenhouse cooling. Greensys symposium, Quebec. Acta Horticulture, in press.

Kaukoranta, T. 2009. Energiavirrat. MTT puutarhatuotannon jukaisematon sisäinen selvitys.

Juntti, Timo. 2009. Lämmitystarve kurkkuhuoneessa. Suullinen tiedonanto.

Montero, J.I. 2006. Evaporative cooling in greenhouses: effect on mikroclimate, water use efficiency and plant response. Acta Horticulture 719: 373-384

Särkkä, L. 2004. Taittaminen eduksi Amadeus-ruusulle. Puutarha \& kauppa 8 (27-28): 17-19.

Särkkä, L. E., Hovi-Pekkanen, T., Kaukoranta, T.,Tahvonen, R. \& Huttunen, J. 2006. Greenhouse Cooling in Summer in Finland - Preliminary Results of Climate Control and Plant Response. Acta Horticulturae 719: 439-445.

Särkkä, L., Luomala, E-M., Hovi-Pekkanen, T., Kaukoranta, T., Tahvonen, R., Huttunen, J. \& Alinikula, M. 2008. Kasvihuoneen jäähdytyksellä parempaan ilmastoon ja satoon. Maa- ja elintarviketalous 122, 102 p. 